\title{
"Tarde demais para morrer jovem": depressão e suicídio na literatura brasileira contemporânea
}

\author{
Rodolfo Rorato Londero ${ }^{1}$
}

\begin{abstract}
Resumo: O objetivo deste artigo é discutir o problema da depressão e do suicí dio depressivo a partir de exemplos da literatura brasileira contemporânea, como os romances Até o dia em que o cão morreu, de Daniel Galera, e Manual da demissão, de Julia Wähmann, e dois poemas de Frederico Barbosa: "Louco no oco sem beiras" e "Desexistir". Para tanto, além de estabelecer diferenças entre melancolia e depressão, busca se identificar a depressão como sintoma da sociedade de desempenho e a literatura como forma de abordar e compre ender esse sintoma. Destaca se o papel que o tempo desempenha na formação da experiência depressiva, fazendo dele elemento privilegiado para se aproxi mar dos exemplos de literatura selecionados e assim aprofundar o debate em questão.
\end{abstract}

Palavras chave: depressão; suicídio; literatura brasileira contemporânea.

Em um de seus primeiros romances, Trapo, Cristóvão Tezza nos fala de um professor de literatura aposen tado que se põe a analisar o valor literário de muitos textos (em sua maioria, cartas de amor) produzi dos por um jovem poeta suicida. Como qualquer crítico literário, o professor inicia sua tarefa analisan do os textos em si, buscando a tal da literariedade, mas quando se perce be mergulhado no desespero do au tor, ele finalmente entende a razão de sua tarefa: "A literatura, mero pretexto. Interessa me a figura tor turada que deu um tiro na cabeça" (TEZZA, 2018, p. 202). A literatura torna se mero pretexto quando es tamos diante do único "problema filosófico realmente sério", como afirma Camus (2018) em seu co nhecido ensaio sobre o absurdo e o suicídio. Entretanto, enquanto pre texto, a literatura pode nos ajudar a compreender esse problema, que Camus também entende como um sentimento, como uma lógica que pode nos levar à morte (CAMUS, 2018, p. 23). Das muitas lógicas do suicídio, este artigo explora apenas uma delas: a depressão. Portanto, o objetivo deste artigo é discutir o problema da depressão e do suicídio depressivo a partir de exemplos da literatura brasileira contemporânea, como os romances Até o día em que o cão morreu, de Daniel Galera, e Manual da demissão, de Julia Wähmann, e dois poemas de Frede rico Barbosa: "Louco no oco sem
${ }^{1}$ Professora Adjun to na UEL. Doutor em Estudos Literários pela UFSM. Contàto: rodolfo londe ro@hotmail.com. 
beiras" e "Desexistir".

Não temos a pretensão de apre sentar análises detalhadas das obras destacadas, até porque seguimos aqui a intuição de Gumbrecht em sua tentativa de revelar atmosferas e ambientes possíveis (Stimimung): "Ao ser acrescentado à experiência da empatia, o ato de leitura com foco no Stimmung deveria ser acompanhado de uma medidal de sobriedade e de moderação verbal. Em muitos casos, mais vale apontar na direção de ambientes possíveis do que descrevê los em seus por menores (muito menos celebrá los)" (GUMBRECHT, 2014, p. 28). Do mesmo modo, ainda que nosso texto esteja viciado pela linguagem científica e recheado de conceitos da teoria psicanalítica, não temos a pretensão de decifrar as obras cita das por meio da chave da depres são, pois "ler em busca de Stimmung não pode significar 'de cifrar' atmosferas e ambientes, pois estes não têm significação fixa" (GUMBRECHT, 2014, p. 30). Tanto o tema da depressão quanto os con ceitos psicanalíticos surgem aqui como textos participantes de um exercício intertextual, portanto, ho rizontal; sem hierarquias. Ainda que rão seja nosso propósito discu tir neste momento a depressão e o suicídio depressivo enquanto exemplo de Stimmung, vale a pena destacar que, ao traduzir Stimmung como a junção das palavras inglesas mood (humor) e climate (clima), Gumbrecht percebe como a palavra alemã reúne "uma sensação interi or" a "alguma coisa objetiva que está em volta das pessoas e sobre elas exerce uma influência física" (GUMBRECHT, 2014, p. 12). É as sim que entendemos a depressão neste artigo: o encontro entre um estado de humor (sendo assim des crita pela psiquiatria) e condições históricas e sociais específicas.

Antes da depressão, contudo, a melancolia já motivava muitos a fazerem a forca em sua própria ca sa, como declama Dante em sua Divina Comédia (Inferno, Canto XIII, verso 1.51). Na verdade, po demos compreender os depressivos como os "remanescentes dos anti gos melancólicos" (KEHL, 2015, p. 16). Entretanto, se podemos perce ber semelhanças entre melancolia e depressão, também devemos perce ber suas diferenças, sendo este o objetivo do primeiro tópico deste artigo. No segundo tópico, explora remos algumas relações entre de prèssão, literatura e sociedade de desempenho (HAN, 2015), buscan do identificar a depressão como sin toma social e a literatura como forma de abordar e compreender esse sintomá, principalmente por meio de suas metáforas. No terceiro tópico, discutiremos o papel revela dor que o tempo desempenha na formação da experiência depressi 'va, e para tanto, nos serviremos do romance de Galera, do qual retira mos o trecho que expressa de forma rigorosa essa experiência: "Tarde demais pra morrer jovem". Ainda no mesmo tópico, também busca remos compreender as relações en tre tempo e depressão a partir do romance de Wähmann e dos poe mas de Barbosa. Por fim, no último tópico, apresentaremos uma peque 
na nota conclusiva, não visando encerrar a discussão promovida nestas páginas, mas mostrar sua contribuição para futuros debates sobre o problema da depressão.

\section{Melancolia e depressão}

Em O tempo e o cão, a partir da teoria e da prática psicanalítica, Kehl (2015) estabelece diferenças entre melancolia e depressão. É cla ro que, no caso de Kehl, essas dife renças são observadas em sua práti ca como analista. No nosso caso, devemos observar se e como a lite ratura fala dessas diferenças. Se le varmos em consideração os grandes momentos da literatura moderna (dos românticos até os dias de hoje), percebemos também essas diferen ças, principalmente se destacarmos o tema do suicídio. A pergunta de cisiva aqui é: ainda podemos mor rer por amor? Dos românticos aos realistas, muitas personagens mor reram por causa ou por consequên cia do amor: o jovem Werther es tourou os miolos por causa de um amor impossível; Madame Bovary se envenenou por jamais encontrar um amor verdadeiro; Anna Kareni na se lançou diante do trem por causa de um amor mal resolvido. Em todos esses casos, podemos falar em espíritos melancólicos, em al mas atormentadas por causa do ob jeto perdido (o amor). Camus afir ma que "o absurdo é essencialmente um divórcio [entre o homem e o mundo]" (CAMUS, 2018, p. 45), sendo o suicídio uma das formas de findar essa separação dolorosa: "À sua maneira, o suicídio resolve o absurdo" (CAMUS, 2018, p. 68). É justamente o mundo divorciado, o objeto perdido, que alimenta o sui cídio melancólico. A produção ima ginária dos melancólicos é bastante ativa, e é essa produção, essa fanta sia de amor impossível, que torna a vida insuportável. Sendo assim, o melancólico não morre porque não consegue suportar o absurdo, a vida sem sentido; ele morre porque a vida sem amor não tem sentido. $\mathrm{O}$ seu mundo é bastante carregado de sentido, de razão, mas infelizmente, para ele, esse sentido se encontra para sempre perdido. Vejamos o caso emblemático do jovem Werther, em seu último encontro com sua amada Carlota:

Dominado pelo desespero, [Werther] pegou as mãos dela [Car lota], apertou as aos seus próprios olhos, depois à testa, enquanto Car lota pareceu sentir fundo a atraves sar lhe a alma o pressentimento do horroroso projeto que ele havia concebido. Os sentidos da moça turvaram se, ela apertou lhe as mãos, voltando a segurá las depois junto ao seio, inclinou se para ele num movimento doloroso e as faces ardentes de ambos se tocaram. O universo desvaneceu se para eles. Werther envolveu a nos braços apertando a ao peito e cobriu seus lábios trêmulos e balbuciantes com beijos furiosos. "Werther!", disse ela com voz abafada e tentando desvi ar se. "Werther!" E com débil mão procurava afastá-lo do seu seio.

"Werther!", ela exclamou enfim, em tom mais imperativo e mais no bre. Werther não pode resistir, dei xou a desprender $\sim$ se de seus braços e lançou se ao chão diante dela co mo um desesperado. Ela levantou se 
bruscamente e, cheia de perturba ção, tremendo entre o amor e a có lera, disse 1 he: "É a última vez, Werther! Nunca mais me vereis". E em seguida, lançando ao miserável um olhar cheio de amor, correu pa ra o quarto ao lado e trancou $\sim$ se dentro dele. Werther estendeu os braços em sua direção, mas não se atreveu a retêfla (GOETHE, 2001, p. 173 174).

Werther não se atreveu a retê la, pois sabia que, a partir daquele momento, a partir daquela última tentativa desesperada em salvar sua própria vida, o amor de Carlota es . tava perdido para sempre. Os bra ços estendidos, em direção ao vazio deixado pelo amor, simbolizam a melancolia tão bem quanto o olhar do anjo de Dürer, perdido no hori zonte. Sabendo que Carlota jamais cruzará seu horizonte, resta a Werther levar a cabo o "horroroso projeto" que sua amada pressentiu em seus olhos. Para o melancólico, a questão é: quem viveria num mundo sem amor?

Pois bem, os depressivos são os sobreviventes desse mundo sem amor. Não é por acaso que o mais famoso relato sobre a depressão, $O$ demônio do meio dia, começa exa tamente com estas palavras: "A de pressão é a imperfeição no amor" (SOLOMON, 2014, p. 15). Do mesmo modo, ao dissertar sobre a Agonia do Eros, Han identifica a depressão como resultado de um sujeito de desempenho marcado pelo excesso de positividade e, por tanto, pela ausência do Outro, $\mathrm{O}$ sujeito de desempenho não reco nhece um Outro a quem culpar, a quem sofrer por amor; para ele, o fracasso resume se à famosa ex pressão "é tudo culpa minha". Co mo Han faz questão de ressaltar, discordando de Benjamin (2013), o capitalismo não é uma religião, pois ele "só é inculpador" (HAN, 2017, p. 25; grifo do autor), ou seja, ele não permite culpar o Outro e expi ar pelo Outro. Daí que "a impossi bilidade de desculpa e expiação é responsável também pela depressão do sujeito de desempenho" (HAN, 2017 , p. 25), pois o sujeito da de pressão é aquele que se fecha em si mesmo: "o sujeito depressivo narcisista está esgotado e fatigado de si mesmo. Não tem mundo e é abandonado pelo outro" (HAN, 2017, p. 10; grifos do autor). O de pressivo não pode morrer por amor porque ele vive num mundo sem amor, ou seja, sem a negatividade necessária para enfrentar o absur do.' Portanto,' ao contrário do me lancólico, o depressivo morre por não encontrar sentido na vida. En quanto a produção imaginária ativa envenena o espírito melancólico, sua escassez (que discutiremos adi ante) torna se fatal para o depressi vo. Porque não é capaz de criar ilu sões, justificativas para viver, o de pressivo é sufocado pelo absurdo.

\section{Depressão, literatura e socie dade de desempenho}

Traçamos essas diferenças inici ais entre melancolia e depressão não apenas para delimitar o tema deste artigo, mas também para mostrar como é possível abordar o problema do suicídio depressivo 
sem reduzi lo exclusivamente à questão patológica. Em A doença como metáfora, Sontag defende a tese de "que a doença não é uma metáfora e que a maneira mais fi dedigna de encará la - e a maneira mais saudável de ficar doénte - é aquela que esteja mais depurada de pensamentos metafóricos, que seja mais resistente a tais pensamentos" (SONTAG, 1984, p. 7 8; grifo da autora). No ensaio em questão, Son tag discute a tuberculose e o câncer, mostrando como ambas as doenças, de forma semelhante, se viram "so brecarregadas com ornamentos da metáfora" (SONTAG, 1984, p. 9). É compreensível a indignação de Son tag - ela mesma acometida por câncer quando escreveu essas li nhas - ao perceber como doenças de origem biológica, mas cercadas de mistério, são transformadas em "fantasias punitivas ou sentimen tais" (SONTAG, 1984, p. 7). Entre tanto, como reconhece Han, a pai sagem patológica alterou se pro fundamente neste começo do século XXI:

Doenças neuronais como a depressão, transtorno de déficit de atenção com síndrome de hiperatividade (Tdah), transtorno de personalidade limítrofe (TPL) ou a síndrome de burnout (SB) determinam a paisagem patológica do começo do século XXI. Não são infecções, mas enfartos, provocados não pela negatividade de algo imunologicamente diverso, mas pelo excesso de positividade. Assim, elas escapam a qualquer técnica imunológica, que tem a funçãó de afastar a negatividade daquilo que é estranho (HAN, 2015a, p. 8; grifos do autor).
A fantasia contagiosa do câncer, tão bem destrinchada por Sontag em seu ensaio, já não se aplica aos enfartos psíquicos de hoje, pois eles não são vivenciados "como malignidade misteriosa" (SONTAG, 1984, p. 10) - o corpo estranho, a negatividade a combater -, mas como o efeito colateral do próprio desempenho, da própria iniciativa e motivação, enfim, do excesso de positividade.

No caso da depressão, a metáfora não serve para esconder essa doença nas sombras da ignorância, mas para destacar seus contornos diante da luz excessivamente científica que hoje a recobre. Pois reduzir a depressão a uma doença de origem exclusivamente biológica, como a indústria farmacêutica costuma fazer, é não perceber que estamos diante de um "sintoma social" (KEHL, 2015). O sofrimento dos depressivos é o mesmo daqueles que, nas palavras de Kehl,' "sofrem de um sentimento de tempo estagnado, desajustados do tempo sôfrego do mundo capitalista" (KEHL, 2015, p. 17). Ou seja, trata se de vítimas que não conseguem acompanhar o ritmo da sociedade de desempenho (HAN, 2015a). É contra essa sociedade de desempenho que a depressão precisa de suas metáforas, pois são elas que oferecem a negatividade necessária para o excesso de positividade em que vivemos. Para Solomon, em relato já meńcionado, "ela [a depressão] só pode ser descrita como metáforas e alegorias" (SOLOMON, 2014, p. 16). Isto porque, ainda segundo o 
autor, "a depressão é um estado quase inimaginável / para alguém que não a conhece. Uma sequência de metáforas [...] é a única maneira de falar sobre a experiência" (SOLOMON, 2014, p. 28).

$\mathrm{Na}$ verdade, ao contrário dos muitós exemplos identificados por Sontag (1984) a respeito da metaforização da tuberculose e do câncer, o mesmo não acontece com a depressão. Wolpert afirma que, "considerando se como a depressão é difundida, são poucas as descrições encontradas no romance inglês", e conclui dizendo que "talvez a depressão seja um quadro tão negativo que os autores tenham evitado descrevê la" (WOLPERT, 2003 , p. 29). Por que se fala tão pouco dessa doença e, consequentemente, de seus casos de suicídio? Ao invés de apostar em explicações fáceis, como tabu ou proibição legal (por exemplo, o Art. 122 do Código Penal brasileiro), entendemos que o excesso de positividade inibe qualquer menção ao problema, mesmo na arena livre da literatura. Quando a depressão se manifesta na literatura, é quase sempre pelo caminho da metáfora, evitando assim que o problema seja neutralizado pelo excesso de positividade.

Não que a palavra "depressão" não apareça aqui ou ali, mas é de conhecimento que "seria útil uma palavra melhor para essa-doença do que alguma que tenha a mera conotação comum de estar 'para baixo" (WOLPERT, 2003, p. 19). Em suas memórias sobre a depressão, Perto das Trevas, William Styron afirma que "depressão" é uma palavra "que passou rastejando pela língua como uma lesma, deixando pouquíssimos traços de sua malevolência intrínse ca e, por sua própria insipidez, im pedindo uma percepção geral da horrível intensidade da doença quando fora de controle" (STYRON apud WOLPERT, 2003, p. 21). Mais uma vez, ao contrário da tese de Sontag (1984), a metáfora serve aqui para compreender uma expe riência que a terminologia médica não consegue descrever apropria da mente. Entre os poucos roman ces que parecem "defender" o ter mo está Extensão do domínio da luta, de Michel Houellebecq: "Ofi cialmente, portanto, estou em de pressão. Parece me uma boa fór mula. Não que eu me sinta muito embaixo. É antes o mundo em torno que me parece muito alto" (HOUELLEBECQ, 2015, p. 123). Contudo, se o narrador "defende" o termo, é apenas para criticar a soci edade ao invertê-lo: a sociedade torna -se insuportável quando esta belece metas, prazos e ideais inal cançáveis. Se a doença mental já serviu como o negativo que afirma positivamente a sociedade (FOU CAULT, 1984), então agora é o 'momento de a doença servir como o positivo que afirma negativamente a sociedade. Nas palavras de Kehl, "talvez por isso a indústria farma cêutica se empenhe tanto em curá lo [o depressivo], em manter igno rado o saber que se esconde sob sua obstinada recusa em inserir se no tempo do Outro" (KEHL, 2015, p. 17). É preciso encontrar na arena livre da literatura indícios desse sa ber perigoso. 


\section{Tempo e depressão}

Como afirma Kristeva, a forma poé tica é “o único 'continente' que pa rece assegurar um domínio incerto, mas adequado, sobre a Coisa" (KRISTEVA, 1989, p. 20). No caso dos depressivos, buscando dar for ma à Coisa, Kehl acredita que "a inadaptação dos depressivos em re " lação às formas contemporâneas de aproveitar o tempo pode ser revela dora da memória recalcada de ou tra temporalidade, própria do 'tem po em que o tempo não contava"” (KEHL, 2015, p. 125). Ainda se gundo a autora,

a extrema lentidão do depressivo, tão incômoda para os que convivem com ele, não deixa de denunciar os excessos de velocidade exigidos pela vida dita normal dos loutros, "os tais sãos", na expressão mordaz de Fer nando Pessoa. (...) $\mathrm{O}$ depressivo busca reencontrar e apropriar $\sim$ se de uma temporalidade que lhe foi rou bada no início da constituição psí quica. (KEHL, 2015, p. 222 223).

Qual é essa temporalidade que foi roubada do depressivo no início de sua constituição psíquica? Para Kehl (2015), o psiquismo surge em função do tempo, do intervalo entre a falta e a satisfação de determinada necessidade. É justamente nesse in tervalo que o imaginário, princi palmente por meio de fantasias, dá forma ao desejo. Entretanto, o que acontece se $\mathrm{o}$ indivíduo é satisfeito sempre de modo imediato, não the restando tempo para fantasiar, para dar forma ao desejo, como ocorre na sociedade de desempenho? Esta é a hipótese de Kehl para explicar o surgimento do sujeito depressivo, bem como sua produção imaginária escassa:

A produção imaginária nos depres sivos é escassa; a pobreza das for mações imaginárias deixa o sujeito à mercê do vazio psíquico. $\mathrm{O}$ de pressivo, que recuou de sua posição fantasmática, teme a fantasia, por tadora de notícias sobre seu desejo. Ao contrário dos neuróticos "co muns" (a não ser nas ocorrências em que se deprimem), o depressivo imagina pouco e, quando ousa fazê lo, logo descrê da fantasia. O vazio depressivo é tributário dessa recusa em fantasiar: o depressivo se vê aba tido pelo desejo recusado, que por isso não se articula através da fanta sia e só se manifesta pela via da an gústia. O desencantamento do de pressivo em relação ao mundo re sulta desse vazio de significação (KEHL, 2015, p. 232).

Ou seja, porque não the é dado tempo para fantasiar, o sujeito de pressivo teme suas próprias fantasi as e o desejo que elas manifestam. A angústia torna se a sua única via desejante (ver mais adiante). Seu desejo é, portanto, o símbolo da fal ta, do mundo vazio de sentido. Po demos entrever algumas das metá foras que revestem e informam essa angủstia, esse vazio de significação, em Até o dia em que o cão morreu, romance de estreia de Daniel Gale ra. Após concluir a faculdade de Letras, $\circ$ narrador protagonista anônimo passa a viver de "bicos" (como professor de inglês e tradutor de russo) e da ajuda de seus' pais. Apesar de seguir o "roteiro à risca" desde que nasceu - colégio, univer sidade, carteira de motorista, etc. -, 
o jovem protagonista sabe que sua vida tomou um caminho diferente do esperado:

Qual o próximo passo? Vamos lá. Conseguir um emprego e ganhar a vida era a continuidade natural des se processo todo. Demorou mais de um ano para eú perceber que não seria assim. (...) Todos os anos ante riores pareceram uma brincadeira idiota, e não havia nenhuma ideia que me estimulasse pro futuro (GA LERA, 2007, p. 33 34).

Sem perspectiva de futuro, como muitos jovens recém -formados, ele torna se uma pessoa reclusa. Con tudo, seus momentos de solidão são quebrados pelas visitas de uma jo vem conhecida por acaso, a modelo Marcela. Apesar de seu interesse por Marcela, ele não consegue esta belecer um relacionamento sério. Como ele mesmo diz, resumindo sua vida profissional, mas também prevendo sua vida amorosa, "o no me disso é inércia" (GALERA, 2007, p. 33).

O ponto máximo desta inércia existencial é assim descrito pelo protagonista: "Permanecia uma ho ra inteira mergulhado dentro da banheira, escutando música, até a água ficar fria. E especialmente ali, dentro d'água, eu me sentia cansa do. Velho, em certo sentido. No'sen tido de que era tarde demais pra morrer jovem" (GALERA, 2007, p. 91). O que acontece quando desco brimos que já é "tarde demais pra morrer jovem"? "O que acontece quando ultrapassamos o tempo que nos foi socialmente estipulado (ar: rumar emprego, casar, ter filhos, etc.), como acontece com o jovem protagonista de Galera? A partir daí, onde nos encontramos? Em que tempo estamos quando o tempo já não é mais tempo? Merleau Ponty (2014) nos diz que as palavras ro deiam o sentido, e é exatamente a sensação que temos quando lemos esse trecho do romance de Galera. Parece que há um sentido para se dizer, mas as palavras não são sufi cientes. Primeiro "cansado", depois "velho", depois "tarde demais pra morrer jovem". "Cansado" não é suficiente, então "velho". "Velho" não é suficiente, então "tarde de mais pra morrer jovem". "Tarde demais pra morrer jovem" não é suficiente, então... é onde estamos agora, buscando mais palavras que possam satisfazer esse sentido. Mas é injusto pensar que uma palavra sucede outra e assim por diante, pois, no final, a tentativa de sentido é esse tatear' por metáforas. Como na velha anedota, o sentido é o elefante que nós, cegos, tentamos des cobrir por meio do tato. Mas não podemos rir da tola tentativa dos cegos, pois, ao contrário da moral da anedota ("não julgue o todo pe las partes"), não há nenhum viden te capaz de confirmar o sentido. Somos todos cegos diante do senti do.

"Tarde demais pra morrer jo vem": para aqueles que sobrevive ram a própria morte, o próprio tempo, enfim, para os depressivos, somente resta o tempo estagnado, pós narrativa. Nem a morte é capaz de alimentar fantasias nos depressi vos, o que significa dizer, da pers pectiva de Bataille (2013), que eles também são carentes de erotismo: a vertigem do abismo da morte não é 
capaz de fascina los, pois estão pre sos no tempo estagnado da experi ência depressiva. A morte não é ca paz de oferecer um fim para eles, ou seja, um tempo narrativo, dotado de ritmo, sentido e aroma, como diria Han (2015b). No caso do ro mance de Galera, a depressão é su perada justamente quando a morte surge ao final da narrativa, como bem ilustra o título Até o dia em que o cão morreu. Quando o seu cão morre, o protagonista decide aceitar o amor representado por Marcela. A morte reintroduz a ne gatividade, o Outro, na vida do pro tagonista. "O eros vence a depres são" (HAN, 2017, p. 12).

Em Manual da demissão, segun do romance de Julia Wähmann, a própria demissão torna $\sim$ se metáfora da depressão (aliás, a rima é ade quada). O tempo estagnado da ex periência depressiva é traduzido pelas longas esperas enfrentadas pela narradora protagonista J., após sua demissão de um emprego inde finido: a longa espera em filas para receber o auxílio desemprego, a longa espera sem nada para fazer, a longa espera para encontrar o pró ximo emprego, etc. E assim o ro mance cumpre o que está expresso em seu título, mostrando todos os passos da demissão. Entretanto, um deles nos chama a atenção, pois fala justamente da depressão do demiti . do:

É a faixa de horário mais infeliz dos míopes: a depressão do demitido começa por volta das $4 \mathrm{~h} 30$ da tarde e se estende até umas sete da noite. Abarca o período que outrora era dedicado a ver vídeos no YouTube, seguido do terceiro café, para então encarar, no mínimo, uma hora de trânsito de volta para casa. Talvez seja a solidão súbita de não ter mais companhia para aqueles momentos em que pandas fazendo gracinhas pareciam imprescindiveis, ou talvez seja o tédio depois de um dia inteiro à deriva, mas desconfio que a causa dessa melancolia angustiada e pon tual seja realmente a dificuldade de enxergar - as coisas e um futuro (WÄHMANN, 2018, p. 58 59).

A narradora pénsa em vários mo tivos para sua depressão pontual, mas, mais uma vez, a falta de pers pectiva é a suspeita vencedora: nes te caso, a depressão é miopia, difi culdade de enxergar um futuro. Mas se o sujeito depressivo demitido realmente desejasse, voltar a trabalhar é o que ele desejaria? A narradora define como "síndrome de Estocolmo". a relação entre o demitido e o seu antigo emprego, pois como desejar o tempo tortu rante do trabalho senão por que o demitido' se encontra intimidado?

Como, enfim, todas as ocasiões que
eu desprezava [do meu emprego] e
que agora não pareciam tão ruins,
porque eram um dos aspectos de
uma vida organizada, com expecta
tivas, perspectivas e menos dificul
dades em responder perguntas sim
ples, como: "O que você faz?"
(WÄHMANN, 2018, p. 122).

Ou melhor, o que você faz com o seu tempo? Quando nada fazemos com nosso tempo, quando simples mente deixamos o mundo ser "Sentada ali num banco a gente não faz nada: fica apenas sentada dei xando o mundo ser" (citação de 
Clarice Lispector retirada do ro mance de Wähmann) -, córremos o risco de vislumbrar o abismo da morte, a negatividade do mundo. Se deixarmos o mundo ser, ele pode nos-devorar. Daí que trabalhamos, trabalhamos, trabalhamos. "A de pressão é o adoecimento de uma sociedade que sofre sob o excesso de positividade" (HAN, 2015a, p. 29).

Ao contrário dos poetas românti cos, que souberam fantasiar com a morte, os poetas contemporâneos recuam diante dessa possibilidade, como sugere o poema "Desexistir", de Frederico Barbosa:

Quando eu desisti

de me matar

já era tarde.

Desexistir

já era um hábito.

Já disparara

a autobala:

cobra cega se comendo

como quem cava

a própria vala.

Já me queimara.

Pontes, estrădas, memórias, cartas, toda saída dinamitada.

Quando eu desisti

não tinha volta.

Passara do ponto,

já não era mais

a hora exata.

(BARBOSA, 2013, p. 367).

É de se esperar que, diante da pergunta fundamental - "se a vida vale ou não vale a pena viver"
(CAMUS, 2018, p. 17) -, o sujeito depressivo titubeie, desistindo de morrer quando já é tarde demais. $\mathrm{Na}$ verdade, a quase homofonia en tre "desexistir" e "desistir" é escla recedora, inclusive da perspectiva psicanalítica: citando Lacan, Kehl afirma que a única culpa legítima é aquela do sujeito que trai sua via desejante - daí que, para a autora, o depressivo é o único que tem razão em se sentir culpado, pois ele recua diante do desejo (KEHL, 2015, p. 194). Portanto, desistir é desexistir, é abandonar a via desejante, ou a "única vida", como afirma Kehl. Como no romance de Galera, a pa lavra "tarde" também está presente no poema de Barbosa, mostrando como o sujeito depressivo está sem pre atrasado, mesmo para o fim. Este atraso é outro modo de desistir, de recuar diante do desejo. E por que ele se atríasou, "passara do pon to, / já não era mais / a hora exa ta". A hora exata é aquela que mar ca algum acontecimento, portanto, é aquela que empresta ritmo e nar rativa para a vida: a hora para acordar, para almoçar, para dor mir, etc. Entretanto, o que falta na experiência depressiva é justamente a hora exata, ou seja, os aconteci 'mentos que emprestam ritmo e nar rativa para a vida.

O tempo estagnado da experiên cia depressiva é um dos temas, se não o principal, do poema "Louco no oco sem beiras", de Frederico Barbosa. A começar pela dificulda de em acordar que, por sua vez, é acompanhada pela dificuldade em dormir, como mostra o trecho abai xo: 
acordo

ao eu

abalo

troco me no tremor

do atraso

de mente névoa o

pedido: cama!

do relógio o

grito: bravo!

$o$ atraso o atraso $o$

duas horas de sono

descompasso

quando muito duas horas

outras tantas horas

passo me decompondo

quantas muitas outras horas

passam com desdém

no eu opaco

(BARBOSA, 2013, p. 338 339).

Esse "o" ao final de alguns ver sos, que também se repete em mui tos outros ao longo do poema, não apenas quebra o ritmo da poesia - a forma traduzindo perfeitamente o conteúdo, ou seja, a quebra do rit mo traduzindo o tempo estagnado dos depressivos -, mas também é um sinal do vazio, do "oco" do títu lo e, por fim, do "zero rarefeito", do "nada". Há um "descompasso" en tre o eu lírico e o tempo, seja por causa do "atraso", seja por causa das poucas horas de sono e das "ou tras tantas" de insônia (ou "insâ nia", como diz um verso mais à frente), seja por causa das "muitas outras horas" que demoram a pas sar, desdenhando de um sujeito fe chado em si, "opaco" para o mundo - o sujeito depressivo narcisista que comentamos anteriormente (HAN, 2017).

Como não poderia faltar, o "reló gio" também está presente nos ver sos acima, representando justamen te o tempo inacessível ao eu lírico, o tempo que transcorre indepen dente de sua vontade. "Desesperta dor" é o neologismo usado pelo eu lírico para se referir a esse tempo, aparecendo duas vezes, uma delas encerrando o poema. O despertador é o desespero do sujeito depressivo, pois o faz lembrar de seu "descom passo" em relação ao tempo. Daí os três versos que evidenciam as rela ções que buscamos estabelecer aqui:

pressão de

ser presa

nessa pressa

depressão

(BARBOSA, 2013, p. 352).

Desta vez o poeta explora a quase homografia entre "pressão", "pre sa" e "pressa", e como essas pala vras parecem residir em "depres são". Somos inclusive levados a pensar que "depressão" é o aumen tativo de "depressa", mas a gravi dade de "pressão" e "presa" desfa zem qualquer tentativa de comici dade trocadilhesca. Pois a pressão de estar preso na pressa resume a experiência e o sintoma social da depressão. Estamos todos presos nessa depressão.

\section{Nota de conclusão}

Sabe -se que, até o ano de 2030, a depressão tornar se á a doença mais comum do mundo, segundo dados da Organização 'Mundial de Saúde (BBC BRASIL, 2009). Se dei xamos para citar esses dados alar mantes ao final de nosso artigo, não 
é porque eles tenham menor impor tância, mas porque acreditámos que eles não deveriam conduzir o deba te aqui proposto. $\mathrm{Na}$ verdade, se iniciamos compreendendo a litera tura como "mero pretexto", não é porque ela deve se rebaixar a um problema como o da depressão, mas porque devemos sempre lembrar o apelo de Todorov em $A$ literatura em perigo: "O conhecimento/da literatura não é um fim em si, mas uma das vias régias que conduzem à realização pessoal de cada um" (TODOROV, 2009, p. 33). Isto não significa transformar a literatura em autoajuda e muito menos em remédio, como sugerem algumas abordagens equivocadas (por exemplo, GALLIAN, 2017). Diante de campanhas louváveis como Se tembro Amarelo e de muitos livros de autoajuda que buscam aliviar o problema da depressão, este artigo seguiu por um caminho diferente, pois acredita que os exemplos cita dos acima enquadram a experiência da depressão e o problema do suicí dio em discursos positivos, ou seja, fazem falar o que a sociedade gos taria de ouvir. É preciso ouvir essa experiência sem o peso desses dis cursos, sendo a literatura um espa ço privilegiado para essa tarefa. Portanto, ao invés de esclarecer, este artigo buscou tão somente ou vir da forma mais atenta possível. É certo que isto não solucionará ne nhum problema de saúde pública, como é o caso da epidemia de depressão, mas acreditamos que o sa ber perigoso oriundo da experiên cia da depressão é capaz de levantar questionamentos e críticas impor tantes ao "culto da performance" que hoje todos nós fazemos (EHRENBERG, 2010).

\title{
"Too late to die young": depression and suicide in contemporary Brazilian literature
}

\begin{abstract}
The aim of this paper is to discuss the problem of depression and depressive suicide from examples of contemporary Brazilian literature, such as novels Até o dia em que o cão morreu, by Daniel Galera, and Manual da demissão, by Julia Wähmann, and two poems: "Louco no oco sem beiras" and "Desexistir", by Frederico Barbosa. Therefore, in addition to establishing differences between melancholia and depression, we seek to identify depression as a symptom of achievement society and literature as a way to approach and understand this symptom. This paper emphasizes the role that time plays in the formation of depressive experience, making it a privileged element to approach the examples above and thus to deepen the debate in question.

Keywords: depression; suicide; contemporary Brazilian literature.
\end{abstract}

\section{Referências}

BARBOSA, Frederico. Na lata: poesia reunida, 1978 2013. São Paulo: Iluminuras, 2013. 
BATAILLE, Géorges. O erotismo. Belo Horizonte: Autêntica, 2013.

BBC BRASIL. Depressão será a doença mais comum do mundo em 2030, diz OMS (2009). Disponível em:

<http://www.bbc.com/portuguese/noticias/2009/09/090902_depressao_oms_ cq $>$. Acesso em: $14 \mathrm{fev} .2018$.

BENJAMIN, Walter. O capitalismo como religião. São Paulo: Boitempo, 2013.

CAMUS, Albert. O mito de Sísifo. Rio de Janeiro: Record, 2018.

EHRENBERG, Alain. $O$ culto da performance: da aventura empreendedora à depressão nervosa. Aparecida: Ideias \& Letras, 2010.

FOUCAULT, Michel. Doença mental e psicologia. Rio de Janeiro: Tempo Brasileiro, 1984.

GALERA, Daniel. Até o dia em que o cão morreu. São Paulo: Companhia das Letras, 2007.

GALliAN, Dante. A literatura como remédio: os clássicos e a saúde da alma. São Paulo: Martin Claret, 2017.

GOETHE, Johann Wolfgang. Os sofrimentos do jovem Werther. Porto Alegre: L\&PM, 2001.

GUMBRECHT, Hans Ulrich. Atmosfera, ambiência, Stimmung: sobre um potencial oculto da literatura. Rio de Janeiro: Contraponto, 2014.

HAN, Byung Chul. Agonia do Eros. Petrópolis: Vozes, 2017.

. Sociedade do cansaço. Petrópolis: Vozes, 2015a.'

Barcelona: Herder, $2015 b$.

HOUELLEBECQ, Michel. Extensão do domínio da luta. Porto Alegre: Sulina, 2015.

KEHL, Maria Rita. O tempo e o cão: a atualidade das depressões. São Paulo: Boitempo, 2015.

KRISTEVA, Julia. Sol negro: depressão e melancolia. Rio de Janeiro: Rocco, 1989.

MERLEAU PONTY, Maurice. A prosa do mündo. São Paulo: Cosac Naify, 2014.

SOLOMON, Andrew. O demônio do meio dia: uma anatomia da depressão. São Paulo: Companhia das Letras, 2014.

SONTAG, Susan. A doença como mëtáfora. Rio de Janeiro: Graal, 1984.

TEZZA, Cristóvão. Trapo. Rio de Janeíro: Record, 2018.

TODOROV, Tzvetan. A literatura em perigo. Rio de Janeiro: DIFEL, 2009.

WÄHMANN, Julia. Manual de demissã̀o. Rio de Janeiro: Record, 2018. 
WOLPERT, Lewis.' Tristeza maligna: a anatomia da depressão. São Paulo: Martins Fontes, 2003.

Recebido em: 03/11/2018 Aprovado em: 15/03/2019 